\title{
Of Parasites and Their Hosts
}

\author{
Okwa 0 Omolade* \\ Department of Zoology and Environmental Biology, Faculty of Science, Lagos State University, Nigeria
}

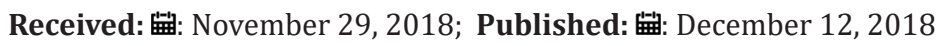

*Corresponding author: Okwa 0 Omolade, Department of Zoology and Environmental Biology, Nigeria

\section{Mini Review}

\section{Host Parasite Relationships}

Parasitism is an association between two different species of organisms, where only one partner which is always the parasite derives benefits metabolically. The other partner is the host and gets nothing in return but harm, damage or death [1]. A parasite lives in a particular way called parasitism. Parasitism as a one-sided partnership in which the host receives no benefits but instead some degree of harm, or death is an ingratitude and is synonymous the parasite committing matricide! An 'ideal' parasite must not even dare kill its host because the death of the host means the death of the parasite. An "ideal" parasite does not even exist because the slightest effects of all parasites are detrimental to their hosts [2]. Caullery [3] considers that "parasitism is a case of balance of power; the parasites and the host form a functional balance system which is placed in opposition to the external environment. Both the parasite and host make the best of a bad job. The host reacts to keep the parasite away or to a minimum while the parasite attempts to live as un-obstructively as possible, despite all the host's reactions which threatens the parasites' existence.

\section{Parasites Metabolic Dependency on the Hosts Could be in Several Ways:}

a) Nutritional: As in Flukes, tapeworms such as Diphyllobothrium latum

b) Developmental stimuli: As in P. intergerrinum and Opalina ranarum , (parasites of frog),

c) Digestive Enzymes: As in tapeworms such as Taenia sp and Echinococus sp

d) Shelter: As in endoparasites such as Plasmodium sp , Entamoeba sp, Ascaris sp e.t.c

e) Movement: As in ectoparasites such as lice, fleas, ticks and mites

f) Control of maturation: As in P. intergerrinum and Opalina ranarum

\section{Parasitism has prolonged effects on Both Hosts and Parasites Such as:}

a) Parasites have mechanisms for locating their host like chemotaxis and active penetration such as Schistosome cercariae and hookworm larvae

b) Transmission of parasites to the new host may be associated with daily or circadian rhythms such as cell division and migrating patterns [4].

c) Parasites have to survive in their host using several mechanisms like encystations, transformation or tail loss as in schistosome cercariae.

d) Parasites have surfaces that play important roles in nutrition. There is usually a major nutritional interface with the host such as the digestive-absorptive epithelium in platyhelminthes which has enormous increase in surface area by development of folds and microvilli such as tubercules, spines and pores of flukes and tapeworms [5].

e) Damage to host can be as a result of immune response (immuno-pathology). This can be more damaging than the infection itself $[5,6]$.

f) Parasites exhibit host specificity and are adapted to infect specific species but cannot invade certain species or strains of host, for example, the malaria parasite Plasmodium yoelli can alone affect mice while Plasmodium falciparium and P. malariae are human specific [7].

Effects of Parasites on their Hosts: Parasites May Injure their Host in a Number of Ways

Toxins: Apart from disease and death, parasites can produce poisonous substances in the form of secretions, excretions or other products such as proteolytic enzymes and pigments. These can harm or sensitize the host, for example, Schistosome cercariae, Entamoeba histolytica and Malaria parasites [5]. 
Mechanical Effects: Mechanical damage due to big size or number of parasites occurs such as the hydratid cysts of Echinoccocus species. Intestinal obstruction, blockage and entangling of worms also occur such as in Ascaris lumbricoides. Parasites can perforate vital organs when migrating as in hookworms and Ascaris. Adhesive structures of parasites also cause mechanical damage as in Taenids.

Absorption of Food: Parasites can deplete the host nutritional level to reach disease level for the host. For example, Diphyllobothrium latum, the broad fish tapeworm absorbs a great quantity of vitamin B12 reaching to megaloblastic anaemia. Hook worm absorbs iron daily leading to iron deficiency anaemia.

Destruction of Host Tissues: Skin penetrating parasites cause skin destruction such as the larvae of hookworm and Schistosomes which causes swimmer's itch and the larvae of myasis producing flies. Microfilariae of Onchocerca volvulus causes skin onchodermatitis, nodules, leopard skin and lizard skin. The skin lesions become the site of secondary bacterial infection $(6,7)$.

Ingestion of Host's Body Constituent: Some parasites such as hookworms and microfilariae of filarial worms feed on the body fluids (blood and lymph), and epithelia cells causing blood and fluid loss.

Gigantism: Some parasites such as larval stages of trematodes enhance growth of their snail intermediate host [1].

Parasitic Castration: Sex reversal and parasitic castration occurs when gonadal tissues of intermediate hosts such as in crabs and snails are destroyed $[1,3]$.

Effects of Hosts on the Parasites (Host reaction): These Effects are not as Apparent as Parasites Effects

Tissue Reaction: These are host defense mechanisms. The tissue reactions are localized in the vicinity of the parasite's invasion. They usually disappear after the invading organism has been eliminated, for example, inflammatory reactions, nodules, induction of abnormal growth, hyperplasia, metaplasia and neoplasia (tumors) and hypertrophy such as in Trichinella spiralis and Onchocerca volvulus infections [5].

Immunity: This is a generalized effect on the body. It can originate in organs or systems remote from the vicinity of the infection. It persists for a long time even after elimination. This is a physiological response directed against the survival of the parasite. Anti bodies are produced to destroy parasites in some cases. Cell mediated immunity by complement activation occurs $[6,7]$ such as in helminthes infections.
Host Specification: Hosts have their own specific parasites. Some parasites are naturally adapted to certain species of hosts. For example, Trypanosoma brucei brucei infects only cattle but Trypanosoma brucei gambiense and Trypanosoma brucei rhodesiense infects humans.

Adaptations: Certain parasites develop certain morphological and drastic modifications to enable them fit to the host. For, example blood flagellates have torpedo shape to enhance swimming. Giardia lamblia has adhesive discs and Taenia solium have hooks to hold fast to the intestinal wall of host.

Host Resistance: Host insusceptibility is the unsuitability of a host as physiology, behavior, and structure Host parasite interactions may also influence host resistance. For example, Plasmodium vivax is not popular among West African because of the duffy factor in their red blood cells [8].

\section{Conclusion}

It is obvious that parasites have undermined the health status of individuals and jeopardized the economic development of nations in tropical Africa leading to poverty [8]. Parasitism is also the major cause of low productivity of livestock and poultry in the tropics. Parasites are 'unwelcomed strangers' because the body reacts and builds a resistance against them. The immune of the hosts fights back against parasites but unfortunately parasites fight back using several mechanisms of evading the host immune system. Only the host with the most vibrant immune systems can fight back successfully. However, the battle continues.

\section{References}

1. Ukoli FMA (1990) Introduction to Parasitology in Tropical Africa. Text flow publishers. ISBN: 978-2783- 005, pp. 462.

2. Caullery M (1952) Parasitism and symbiosis. Sidgwick and Jackson pp. 340.

3. Otubanjo OA (2007) Elements of Parasitology. Panaf publishers ISBN: 978-370-498-2, pp. 196.

4. Levine ND, Collins JO, Cox FE, Deroux G, Grian J, et al. (1980) A newly revised classification of Protozoans. Journal of Protozoology 27(1): 3758.

5. Cox FEG (2004) Modern parasitology: A textbook of Parasitology edited by F.E.G Cox (Second Edition) Oxford Blackwell scientific Publication. ISBN: 0632-02585-9, pp. 276

6. Oyerinde JPO (1999) Essentials of tropical medical parasitology: University of Lagos Press, Akoka. ISBN: 978-017-615-2, pp. 435.

7. Smyth JD (1994) Introduction to Animal Parasitology (Third edition): Cambridge University press. ISBN: 0521428114, pp. 549.

8. Okwa 00 (2016) The Biology of the Tropical Parasites. Lambert Academic Publishing, Germany. ISBN: 978-3-330-00888-5, pp. 145. 


\section{ISSN: 2574-1241}

DOI: $10.26717 / B J S T R .2018 .12 .002188$

okwa 0 Omolade. Biomed J Sci \& Tech Res

(c) (i) This work is licensed under Creative

Submission Link: https://biomedres.us/submit-manuscript.php

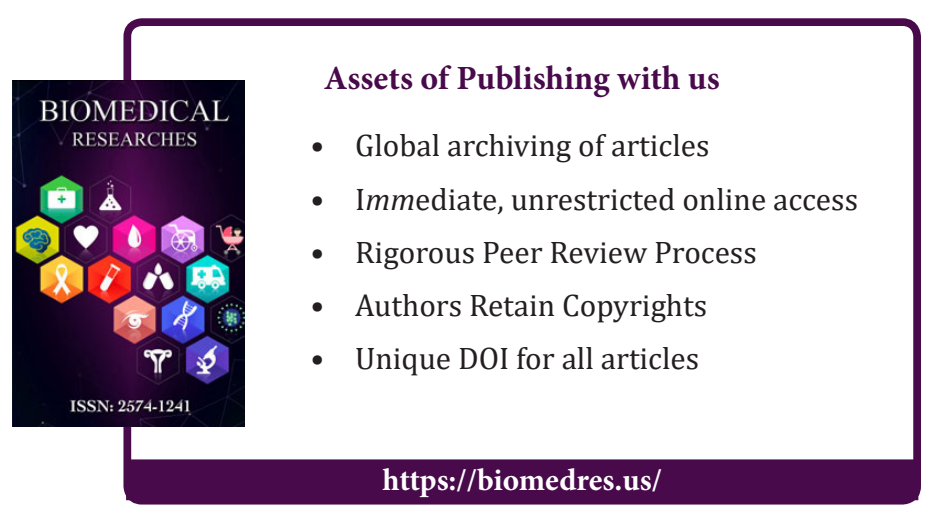

